\title{
Global leadership competencies: a review and discussion
}

\author{
Tiina Jokinen \\ Department of Management, University of Vaasa, Vaasa, Finland
}

\begin{abstract}
Purpose - From the competency point of view, this article aims to review and discuss existing global leadership and other related literature, and to combine findings and suggestions provided in previous literature in a more integrative framework of global leadership competencies.

Design/methodology/approach - The paper reviews and discusses the terminology used in the international global leadership literature. This is followed by a review of the main outcomes of previous research. Finally an attempt is made to combine these outcomes into a more integrative framework of global leadership competencies, offering suggestions for further research.

Findings - This paper provides information about previous research, integrating earlier findings into a more comprehensive framework of global competencies. It also discusses deficiencies in use of terminology and research methods used in earlier studies giving suggestions for further research.

Research limitations/implications - The references used for this review are not an exhaustive list and majority of them are drawn from American journals publishing within the topic area. Relevant sources of information may also exist in other domains of scientific inquiry.

Practical implications - The framework provided in this paper incorporates main findings of previous research and, as such, it may serve as a starting point for practitioners in planning of different selection, training, and career development activities, and for academics in starting their research.
\end{abstract}

Originality/value - This paper fulfils an identified information/resource need.

Keywords Leadership, Globalization, Competences

Paper type Literature review

\section{Introduction}

Understanding international interaction is essential for transnational organizations to work effectively in today's global business environment. The level of this understanding is related to possession of international competencies within an organization (Gupta and Govindarajan, 2002). Although the need to develop leaders with adequate competencies has become obvious in recent years (Adler and Bartholomew, 1992; Brake et al., 1995; Brake, 1997; Morrison, 2000; Bonnstetter, 1999; Suutari, 2002), there is still a significant gap between the international human resource requirements of global strategies and their realization (Adler and Bartholomew, 1992; Engle et al., 2001, Morrison et al., 1999). Furthermore, diversity and complexity increase also in a domestic working environment as business operations become more international. The dynamics, complexity and diversity, now characteristic of global environment, are diffusing into the domestic environment (Gregersen et al., 1998; Harvey and Buckley, 2002) making increasing demands on management and leadership competencies at all organizational levels. Therefore, increasing understanding of different aspects of globalization and interrelationships of various factors and their changes will help organizations to

Received January 2004

Revised October 2004

Accepted October 2004

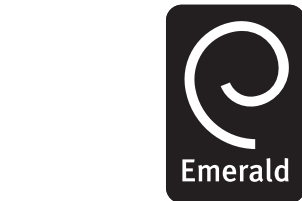

Journal of European Industrial Training

Vol. 29 No. 3,2005 pp. $199-216$

(C) Emerald Group Publishing Limited 0309-0590 
JEIT

29,3

200

meet the new challenges brought by globalization, whether their primary operation environment is domestic, international or global. "Employees need to learn about culture and cross-cultural communication if they are to work effectively with minorities within their own society or with foreigners encountered at home or abroad" (Harris and Moran, 1987).

The development of global competencies should be based on the global business strategy which determines what kind of global presence is desirable, how many and what types of international or global jobs, projects, task forces, and other types of interactions exist (McCall and Hollenbeck, 2002). Competency development process should start from an analysis of the dynamics of the global business environment and the core competencies, continuing to identifying the profiles of necessary human resources and ending with identification of necessary competencies for specific jobs/functions. Once the specific leader competencies have been identified, the next step is to build bench strength effectively (Brake, 1997; Gregersen et al. 1998).

It has been frequently argued that many managers successful in domestic operations do not, for some reason, succeed in the international arena. The question is: why? What, then, are the competencies required in the global context? There are two basic approaches to this question. First, one may assume that global leaders have competencies different from those needed in the domestic context. The other assumption is that global leaders have just developed their (general) competencies into a higher (global) level. Bartlett and Ghoshal (1992), and Baruch (2002) argue that there is no such thing as a "global manager", or any universal criteria for global managers. Instead, Bartlett and Ghoshal see global management as being a task of "a network of specialists including business managers, country managers and functional managers". Yet, they suggest that the top executives are the leaders who manage the complex interactions between the three types of managers, and they must understand the strategic importance of each specialist. Baruch states that the question is only about conventional managers with a "global mindset" - the capacity for appreciating elements of different cultures. Basing on above, it seems that the role of a global leader or manager does exist, no matter what the person(s) playing it is called.

The majority of the research on international assignments and positions has been research about expatriates. Some authors have stated explicitly their focus being on "global" managers/leaders and yet, discuss issues related to the "target country" such as cultural distance. However, a global leader (or manager) is not necessarily an expatriate, and vice versa. The value of an expatriate assignment as a major developmental experience for those pursuing global career is widely acknowledged. Therefore, and because of scarcity of "pure" global leadership literature, expatriate literature - as well as general leadership literature - is relevant also when studying global leaders.

Overall, the previous research on global leadership competencies has been dispersed and more synergistic research is needed, together with a more comprehensive theoretical framework, to understand the processes and interactions underlying the development of a global leadership potential. This paper attempts to take a step towards such framework.

The structure of the paper is as follows. The terminology used in the international/global leadership literature is reviewed and discussed first. This is 
followed by a review of the main outcomes of the previous research. Finally, an attempt is made to combine these outcomes into a more integrative framework of global leadership competencies. Suggestions for further research follow.

The terminology used in the international/global leadership literature

The research on global leadership competencies is characterized by missing consensus on concise definitions and classification of such fundamental terms as "global", "management", "leadership", and "competency". The term "global" is frequently used interchangeably with the terms "international", "multinational" and "transnational" although distinction has been made between these terms (Bartlett and Ghoshal, 1989, Adler and Bartholomew, 1992). Literally, the term "global" refers to something "pertaining to the whole world, world-wide, universal and comprehensive" (The Random House College Dictionary). Also, the words "management" and "leadership" are being used interchangeably, although there is a high level of consensus about the distinction of these terms (i.e. Kotter, 1990a, b, 1999). Kets de Vries and Florent-Treacy (2002)) describe global leadership as a combination and expansion of the two basic roles of manager and leader.

Another issue related to the distinction between management and leadership is the individual's position in the organization. In some research the global leader has been defined through formal position in organization, often focusing on the top executive level only, even just CEOs. However, if there is a significant lack of global leadership competencies, as researchers have argued, people holding executive positions in organizations do not necessarily have the level of global competencies actually required. "...the greatest risk of the 1990s is that companies are trying to implement third generation strategies, using second generation organizations with first generation managers" (Bartlett and Ghoshal, 1992). The definition of global leaders can also be approached through the internationalization level of their responsibilities and activities. In this case, a global leader is anyone having global responsibility over any business activity and global leaders can be found also in lower levels of organization.

Competencies have been defined with terms describing certain personal traits, behaviors, skills, values, and knowledge, and many existing frameworks are combinations of these. In existing research, different types of dimensions have often been mixed and treated as equals. A certain trait in one framework is replaced with corresponding behavior in another. Generally, selection of relevant competencies has generated much argument since the relevance of competencies is commonly seen to vary with the task and organization involved (McBeath, 1990; Baruch, 2002; Evans et al. 1989). In this paper global leadership competencies are seen as those universal qualities that enable individuals to perform their job outside their own national as well as organizational culture, no matter what their educational or ethnical background is, what functional area their job description represents, or what organization they come from. In an attempt to build a more integrative framework for global leadership competencies, this paper attempts to apply a more synergistic approach and focus on similarities across a variety of results (Adler, 1983), and on finding those types of competencies that are necessary when working across cultures - globally. The main outcomes of the literature review are presented next. 
JEIT

29,3

202

\section{The main outcomes of previous research}

Recent research supports the idea that there are a limited number of key competencies, over and above the contextual ones, that predict successful behavior in a global environment (Jordan and Cartwright, 1998; Gregersen et al., 1998). As was already mentioned earlier, most of the previous research regarding international competencies has been done on and among expatriates, but much of this research is also relevant when studying global leaders.

Russell's (1978, in Harris and Moran, 1987, pp. 226-227) review of earlier literature produced nearly 70 "dimensions of overseas success" of which 21 are given priority as being more important for foreign employment. However, this listing focuses on filling specific expatriate positions, including many practical and contextual items such as adaptability of spouse, promotability, interest in host culture etc. Harris and Moran (1987) focus on cross-cultural interaction and suggest that the main outcomes of cross-cultural training can also be used as selecting criteria for overseas service. These are empathy, openness, persistence, sensitivity to intercultural factors, respect for others, role flexibility, tolerance of ambiguity, and a two-way communication skill. Srinivas (1995) defines eight "components of global mindset" which form the base for competencies needed to meet the challenges organizations/individuals face especially when entering a global environment. The components are: curiosity and concern with context, acceptance of complexity and its contradictions, diversity consciousness and sensitivity, seeking opportunity in surprises and uncertainties, faith in organizational processes, focus on continual improvement, extended time perspective, and systems thinking. Rhinesmith (1996) has identified six characteristics of global mindset that lead to global competencies. These are: bigger, broader picture (leading to managing competitiveness), balancing contradictory demands and needs (managing complexity), trust in networked processes, rather than in hierarchical structures (managing adaptability), valuing multicultural teamwork and diversity (managing teams), flow with change/seeing change as opportunity (managing uncertainty), and expanding knowledge and skills, being open to surprises (managing learning).

For globalization, Moran and Riesenberger (1994)) have suggested that leaders should have a global mindset, work as an equal with persons with diverse backgrounds, have a long-term orientation, facilitate organizational change, create learning systems, motivate employees to excellence, negotiate conflicts, manage skillfully the foreign employment cycle, lead and participate effectively in multicultural teams, understand their own values and assumptions, accurately profile the culture of others, and demonstrate knowledge and respect for other countries. Brake's (1997) model of "Global Leadership Triad" consists of four broader categories that are relationship management, personal effectiveness, business acumen, and in the core, the transformational self. Very similar is Gregersen et al.'s (1998) and Black et al.'s (1999) definition of "a core set of global leadership characteristics" that include exhibiting character, embracing duality and demonstrating savvy with inquisitiveness as driving force in the core. In the same line, Rosen (2000) maintains that globally literate leaders possess four "global literacies". These include personal, social, business, and cultural literacy.

Jordan and Cartwright (1998)) maintain that the key to international success lies in a mixture of personality characteristics and managerial competencies. They propose that the "determinant of global competencies" is the psychological profile of stable 
personality traits, comprising four attributes: intellectual capacity, self-confidence, openness to experience and emotional stability. Managerial competencies include relational abilities, cultural sensitivity, linguistic ability, and ability to handle stress. Conner (2000) also identifies a number of "skills and capabilities needed by leaders working in a global company", organizing them under six headings: business savvy, ability to use personal influence, global perspective, strong character, ability to motivate people, and entrepreneurial behavior. Mumford et al. (2000) have defined five categories of "leadership skills for the changing world". In addition to social judgment skills, social skills, and creative problem solving skills leaders need four types of knowledge: knowledge related to task, business, organization and people. The fifth item is willingness to exercise these skills.

Caligiuri and Di Santo (2001) have approached the desired competencies from a company perspective and identified eight desired developmental dimensions for global leadership programs: ability to transact business in another country, ability to change leadership style based on the situation, knowledge of the company's worldwide business structure, knowledge of professional contacts worldwide, knowledge of international business issues, openness, flexibility, and ethnocentrism (getting away from it). Spreitzer et al. (1997) focused on finding candidates for those leadership programs, individuals possessing "global leadership potential". They have identified 14 dimensions or "themes underlying success as an international executive", making a clear distinction between the end-state skills and the ability to learn from experience. The end-state skills include broad business knowledge, sensitivity to cultural differences, courage to take stand, ability to bring out the best in people, acting with integrity, insightfulness, commitment to success and risk taking. Learning ability consists in using feedback, being cross-culturally adventurous, seeking opportunities to learn, openness to criticism, seeking feedback and being flexible. Goldsmith and Walt (1999) emphasize the following six competencies as "the desired characteristics of the leader of the future": thinking globally, appreciating cultural diversity, demonstrating technological savvy, building partnerships, and sharing leadership.

Apparently, there is a problem of missing consensus of the global leadership competencies. Kets de Vries and Florent-Treacy (2002) maintain that excellent domestic leaders often have the same qualities as global ones, but that excellent global leaders are able to "retain these capabilities even in completely unfamiliar situations" (see also Ballardine, cited in Thaler-Certer, 2000). Kets de Vries and Florent-Treacy (2002) refer to the global leaders as ones who possess emotional global intelligence, leaving, however, the precise definition of this characteristic unclear. Boyatzis et al. (1999) suggest that "Emotional intelligence is observed when a person demonstrates the competencies that constitute self-awareness, self-management, social awareness and social skills at appropriate times and ways in sufficient frequency to be effective in the situation.".

These same items appear the most frequently in existing competency frameworks which indicates that emotional intelligence represents a major component of global leadership competency. Much in line with the above definition of emotional intelligence is also Meldrum and Atkinson (1998) description of higher order competencies or meta-abilities as "personal attributes which underpin, and determinate how and when, knowledge and skills will be used". Their classification of meta-abilities includes the following three dimensions: 
JEIT
29,3

204

(1) cognitive skills (ability to see things in many different ways, and self-knowledge as ability to understand and manage oneself);

(2) emotional resilience (ability to maintain confidence and objectivity under difficult circumstances); and

(3) personal drive (determination to succeed, to be proactive and take personal risks).

It can be concluded that there are many listings of global leadership competencies, containing items very similar to the previous examples. The various terms used reflect only semantic differences of the recurrent items presented in the given examples. Many of existing frameworks combine personal traits, behavioral skills, and knowledge into the same model indicating that "competencies are configurations of behavior, attitudes, beliefs, knowledge, intelligence and skills" (Bonnstetter, 1999). In the global context, technical expertise, factual knowledge and customer or shareholder orientation seem to gain much less attention than the "soft" qualities such as self-awareness, self-mastery, flexibility, and social skills. Many authors share the view that although the increasing need for global leaders is clear, the specific competencies of these leaders are far from clear (see, for example, Morrison, 2000 and Jordan and Cartwright, 1998).

Towards a more integrative framework of global leadership competencies After the review of existing frameworks and literature, three main types or levels of global leadership competencies could be identified. First, there are items that are seen as fundamental to the development of other characteristics (Goleman, 1998, Gregersen et al., 1998; Black et al., 1999; Brake, 1997; Spreitzer et al., 1997). They represent thus more the global leadership potential than the end-state competencies. In this paper, they are called the "core of global leadership competencies", and include self-awareness, engagement in personal transformation, and inquisitiveness. Second, there seem to be characteristics that affect the ways in which one approaches different issues. They play a major role in guiding the concrete actions and behavior. These "desired mental characteristics of global leaders" consist of optimism, self-regulation, social judgment skills, empathy, motivation to work in international environment, cognitive skills, and acceptance of complexity and its contradictions. Third, there are more explicit skills and tangible knowledge that refer to concrete actions and producing visible results. Here, they are called "desired behavioral competencies of global leaders" and include social skills, networking skills, and knowledge.

Although the researchers focusing on leadership competencies have described the importance and causalities or different competencies, they have not often been explicit about the process by which the competencies affect the performance outcome. This discussion may be carried out more extensively in other scientific areas, such as psychology. Next, each item is described in more detail. In the following discussion, also general leadership and expatriate literature are used in addition to global leadership literature to get a better picture of the competencies in question.

The core of global leadership competencies

Based on earlier literature, the fundamental global leadership competencies are self-awareness, engagement in personal transformation and inquisitiveness. They are 
viewed as conditions, the driving force, for the emergence of a wide range of other competencies.

Self-awareness. Self-awareness means that a person has a deep understanding of his/her emotions, strengths and weaknesses, needs and drives, sources of frustration and reactions to problems (Schein, 1978; Goleman, 1998). Schein (1978) maintains that one has to become aware of one's own defensiveness and its operation before one can realistically assess one's problem or what one's resources are to deal with it. Self-insight enables one to listen to others and assess the value of what they have to offer. This is also related to openness and value diversity (Spreitzer et al., 1997; Rhinesmith, 1996). Both Schein (1978) and Goleman (1998) state that self-awareness is fundamental to self-regulation and social awareness, which in turn are fundamental to social skills required for effective relationships management (Goleman in Bernhut, 2002).

The importance of self-awareness has been referred to and supported by a number of researchers in terms such as maturity (Brake, 1997), self-confidence (Spreitzer et al., 1997; Jordan and Cartwright, 1998; Mumford et al., 2000; Goleman, 1998 and 2000), personal mastery (Goldsmith and Walt, 1999), well developed ego and self-concept (Srinivas, 1995), confidence in one's capabilities, hardiness and courage to take a stand (Spreitzer et al., 1997), and as a self-depreciating sense of humor Kets de Vries and Florent-Treacy, 2002 Self-awareness has also been described as understanding one's image of one's self and role (Harris and Moran, 1987), understanding one's own values and assumptions (Moran and Riesenberger, 1994), exhibiting character (Black et al., 1999), and questioning one's own assumptions (Srinivas, 1995). Knowing one's strengths and weaknesses is viewed as essential for conscious personal transformation and development. In other words, we cannot change what we don't know. Gupta and Govindarajan (2002) maintain that the more explicitly self-conscious we are, the more likely our current mindset is to change.

Engagement in personal transformation. Brake (1997) connects this phenomenon with the "entrepreneurial spirit". He describes it as commitment to the ongoing development of personal knowledge and skills, creative dissatisfaction, and "drive" to stay up to date. In personal effectiveness, Brake includes items such as strong, intrinsic desire to experience new things, avoiding limiting assumptions, and reflective learning, which can all be seen as reflections of engagement in personal transformation. Spreitzer et al. (1997) emphasize the proactive approach to learning and accepting responsibility for one's own learning. They stress the importance of seeking opportunities to learn and being open to criticism. Seeking out the novel and unusual, a sense of adventure, and a desire to experience new things (Spreitzer et al., 1997) also indicate the same positive attitude and proactive approach to learning. According to Srinivas (1995), successful global leaders focus on continual improvement. Mumford et al. (2000) also discuss a similar trait, stressing the importance of achievement and mastery motives, motivation to extend one's performance capabilities, and openness. Engagement in personal transformation is also referred to as openness to change (Jordan and Cartwright, 1998) and willingness to alter personal attitudes and perceptions (Harris and Moran, 1987). Spreitzer et al. (1997) state that the outcomes of this type of traits and behavior depend on one's ability to learn from experience. 
JEIT

29,3

206

Inquisitiveness. Inquisitiveness (Gregersen et al., 1998; Black et al., 1999) has been referred to by many authors in terms such as curiosity (Srinivas, 1995; Brake, 1997; Spreitzer et al., 1997; Gregersen et al., 1998; Mumford et al., 2000, Gupta and Govindarajan, 2002) and concern with context (Srinivas, 1995). Brake (1997) states that global leaders seek knowledge and expertise beyond boundaries, and draw information from many sources in many ways.

The relationship between inquisitiveness and engagement in personal transformation is reciprocal. Spreitzer et al. (1997) emphasize the importance of seeking information and feedback to support personal development. According to Harris and Moran (1987), inquisitiveness is essential to acquiring knowledge of cultural influences on behavior, patterns, themes, or universals. Inquisitiveness also affects a person's motivation and willingness to enter unfamiliar situations and confront new things (Rhinesmith, 1996; Gregersen et al., 1998), thus having a positive effect on learning. Lastly, inquisitiveness itself can act as a motive for risk taking, initiative and commitment (Srinivas, 1995).

Self-awareness, engagement in personal transformation, and inquisitiveness form the core of global leadership competencies. The desired mental characteristics of global leaders are viewed next.

\section{Desired mental characteristics of global leaders}

Desired mental characteristics of global leaders are characteristics that affect the way an individual attempts to influence others and approaches a certain task. They play the major role before any concrete action takes place, and consist in optimism, self-regulation, social judgment skills, empathy, motivation to work in an international environment, cognitive skills, and acceptance of complexity and its contradictions.

Optimism. Optimism means a "tendency to look on the more favorable side of happenings or possibilities", and the "belief that good ultimately predominates over evil” (The Random House College Dictionary). Goleman (1998) has discussed optimism as a base for motivation: one feels motivated only for what one thinks is possible. Brake (1997) refers to optimism with his notions of taking initiative and maintaining a positive and proactive "can-do" attitude under complex circumstances. Optimism has also been related to ability to manage uncertainty (Rhinesmith, 1996), seeking opportunity in surprises and uncertainties (Srinivas, 1995), risk taking and ability to use problems as a vehicle for growth, "failing forward" (Mumford et al., 2000; Jordan and Cartwright, 1998), learning from mistakes, and courage (Spreitzer et al., 1997).

Self-regulation. Goleman (1998) defines self-regulation as "ability to control or redirect disruptive impulses and moods", both negative and positive, and as "propensity to suspend judgment to think before acting". Self-regulation is the common nominator for a number of items such as emotional stability and ability to cope with distractions (Srinivas, 1995; Jordan and Cartwright, 1998), integrity, character, and accountability (Gregersen et al., 1998; Bennis and Thomas, 2002; Spreitzer et al., 1997; Brake, 1997), adaptive capacity (Bennis and Thomas, 2002; Harris and Moran, 1987; Mumford et al., 2000; Spreitzer et al., 1997; Jordan and Cartwright, 1998), behavioral flexibility (Mumford et al., 2000; Spreitzer et al., 1997; Rhinesmith, 1996; Bonnstetter, 1999), responding to dynamics of social setting (Mumford et al., 2000), flexibility in meeting needs (Srinivas, 1995), tolerance for ambiguity, low neurotism (Gregersen et al., 1998; Mumford et al., 2000; Jordan and Cartwright, 1998), ability to handle stress, 
perseverance, resilience, "hardy" personality (Jordan and Cartwright, 1998), ability to retain capabilities even in completely unfamiliar situations (Kets de Vries and Florent-Treacy, 2002), open-mindedness (Spreitzer et al., 1997), avoiding ethnocentrism (Harris and Moran, 1987), self-efficacy (Spreitzer et al., 1997), good sense of timing, and knowing when to act and when to gather more information, (Brake, 1997; Gregersen et al., 1998).

Social judgment skills. Social judgment skills refer to "seeing the big picture", or taking a perspective, which have been described by many authors as one of the key leadership competencies, whether in a domestic or an international context. Perspective taking capacity is important in two different ways. First, it refers to ability to extend the context beyond a particular problem or situation, which has a positive effect on learning capacity (Yukl, 1994). This way, it also helps in observing and accurately profiling the culture of others. Second, it refers to acknowledging that any solution is implemented and applied in distinctly social contexts (Mumford et al., 2000). According to Mumford et al. (2000), social judgment skills include understanding and monitoring social systems, social perceptiveness, perspective taking capacity, wisdom, self-objectivity, self-reflection, systems perception, awareness of solution fit, judgment under uncertain conditions, systems commitment, awareness of different constituencies, settings and dynamics, identification of restrictions, analysis of downstream consequences, coordinating multiple activities, and sensitivity to relevancy of goals.

Social judgment skills are also referred to in terms such as awareness of different constituents, ability to switch perspectives and understand global interdependences (Brake, 1997), political awareness (Boyatzis et al. 1999), social and organizational awareness (Goleman, 2000), drive for a broader picture (Rhinesmith, 1996), ability to understand cause-effect chain reactions, and long term orientation (Srinivas, 1995; Moran and Riesenberger, 1994).

Empathy. Empathy concerns one's ability to interact with others (Goleman, 1998). It means being participative and sensitive to others' needs and assumptions (Harris and Moran, 1987; Srinivas, 1995; Rhinesmith, 1996), having genuine concern for others (Gregersen et al., 1998), participative warm-heartedness, and respect (Jordan and Cartwright, 1998). It can be seen both as an antecedent and an outcome of an open and flexible approach to others (Harris and Moran, 1987), goodwill (Gregersen et al., 1998), social commitment (Mumford et al., 2000), and service orientation (Goleman, 1998, 3). The level of empathy has a strong influence on such skills as ability to cope with people and situations, emotionally connecting with people from various backgrounds, listening skills and ability to understand different viewpoints, and understanding people (Gregersen et al., 1998). It leads to cross-cultural sensitivity, and expertise in hiring, building, motivating and retaining talent in different cultures (Goldsmith and Walt, 1999; Goleman, 1998 and 2000). In describing the global leadership process, Bonnstetter (1999) uses the analogy of "horse-whispering" where the goal is to maintain spirit by "exploiting" the horse's natural characteristics, such as the needs for security, affiliation and curiosity, to make it freely and voluntarily, even on its own initiative, behave in the desired direction.

Motivation to work in an international environment. Yukl's (1994) description of "commitment" consists of personal drive, goal orientation, perseverance and dedication. Willingness, defined through self-awareness (Goleman, 1998), to enter 
JEIT

29,3

208 situations and exercise different global leadership competencies is an important outcome of motivation and base for learning and developing necessary skills (Yukl, 1994). It may also be the fundamental factor affecting the entire career choice. As Schein (1985) points out, people often select a career for all the wrong reasons, and find their working environment incompatible with their true values. This situation results in feelings of unrest and discontent and in lost productivity. In addition, one's own motivation is commonly seen as prerequisitive for being able to motivate others.

Cognitive skills. Cognitive skills influence the way we experience and interpret our environment. They also have an effect on how much and how effectively we learn from those interpretations and experiences. Wills and Barham (1994) identified "cognitive complexity" as core competence of international managers. International environment is commonly characterized by increased uncertainty and complexity. In this context, routine applications of extant knowledge are not appropriate (Gregersen et al., 1998). Instead, relevant knowledge and representations from previous experiences need to be reformed to generate new creative solutions. Also, in a very dynamic global environment, managers must have divergent thinking skills, be able to switch their focus of concentration quickly from one thing to another (Mintzberg, 1975), and have the capacity of pattern recognition, to identify key fact and anomalous observations, speed of closure, and intelligence. These can be related to different activities such as evaluating performance and strategic options, designing strategies, plan formulation, and making well-reasoned decisions. Spreitzer et al. (1997) emphasize individuals' ability to learn and acquire new skills and competencies, especially when it comes to developing global leadership potential.

Acceptance of complexity and its contradictions. Acceptance of complexity and its contradictions describes a personal attitude towards the ambiguous and unpredictable. It is essential in that it legitimizes the need for learning and thus creates motivation for personal development. Srinivas (1995) defines acceptance of complexity and its contradictions as seeing opportunity in adversity, using diversity to stimulate creativity, and being capable to lead life on many levels.

One of the major factors increasing complexity in global environment, especially when it comes to human resources, is cultural differences between nations, organizations and different sub-groups. Acceptance of complexity and its contradictions enables appreciation of cultural differences which in turn is seen as a fundamental "must have" characteristic of global leaders (e.g. Goldsmith and Walt, 1999; Jordan and Cartwright, 1998; Spreitzer et al. 1997). According to Rhinesmith (1996) acceptance of complexity and its contradictions is essential in order to manage the complexity and contradictions. Combined with a positive attitude, it leads to appreciating the influences of cultural conditioning (Harris and Moran, 1987), embracing duality (Black et al., 1999), an attempt to create opportunities to broaden perspective on local and global challenges (Brake, 1997), and increased ability to manage tensions and to balance global vs. local needs (Gregersen et al., 1998).

After discussing the core and mental level global leadership competencies, the behavioral level global leadership competencies are described next.

The behavioral level global leadership competencies

The behavioral level global leadership competencies are related to abilities to perform concrete actions and producing visible results. They are the outcomes of and more 
explicit in nature than the "core of global leadership competencies" and the "desired mental characteristics of global leaders" discussed above. The behavioral level global leadership competencies include social skills, network management skills, and knowledge.

Social skills. Both, the social skills and networking skills are frequently discussed under the single term of "relationship management". Here, a distinction is made between the two approaches. Compared with networking skills, which will be discussed next, the social skills emphasize the more informal, person-to-person interaction.

In the hallmarks of social skills, Goleman $(1998,2000)$ includes effectiveness in leading change and being a change catalyst, ability to take charge and inspire with a compelling vision, visionary leadership, developing others, conflict management, expertise in building and leading teams, teamwork and collaboration, communication and listening skills, persuasiveness and ability to influence, building bonds and finding a common ground with all kinds of people. Jordan and Cartwright (1998) description of social skills includes moderate extroversion, listening skills, ability to interact with other people, managing first impressions, and multicultural communicative competence. Moran and Riesenberger (1994) maintain that socially skillful mangers are able to motivate employees to excellence, negotiate conflicts, and lead and participate effectively in multicultural teams. Mumford et al. (2000) refer to social performance skills that include communication, persuasion, negotiation, and conflict management. Similarly, Brake's (1997) definition of social skills include influencing, cross-cultural communication, conflict management, negotiation, inspiring others, fostering collaboration, and change agentry. Bennis and Thomas (2002)) emphasize the influencing ability referring to social skills as ability to engage others in shared meaning and express oneself with a distinctive and compelling voice. According to Spreitzer et al. (1997), interpersonal skills help leaders in bringing out the best in people, increasing their capability for cooperation and team building, ability to attract and develop talent, capacity to motivate and align people to one vision, and oral and written communication.

Overall, social skills are outcomes and culminations of other dimensions of emotional intelligence, and combine logical intelligence, emotional intelligence and technical skills into coherent global leadership competence. Social skills make it possible to get the work done through other people and to move people in the desired direction (Goleman, 1998).

Networking skills. As was noted above, the networking skills refer to an other approach to "relationship management" than social skills. It is more related to formal relationships, created and maintained on an organizational rather than personal level. Networking skills are referred to by items such as building and maintaining networks (Srinivas, 1995), building partnerships and alliances (Brake, 1997; Goldsmith and Walt, 1999), building relationships and linking capabilities and activities globally (Jordan and Cartwright, 1998), pursuing partnerships actively, building connections, creating internal networks, and community building (Brake, 1997).

Knowledge. The knowledge of tasks at hand refers to the type of technical knowledge needed to perform certain tasks, that is, to fill the job description. The knowledge of tasks is also described with such terms as computer skills (Goldsmith and Walt, 1999), language skills (Barham and Oates, 1991 and 1992; Wills and Barham, 
JEIT

29,3

210

1994; Coulson-Thomas, 1992; Birchhall et al., 1996; Spreitzer et al, 1997; Conner, 2000; Kets de Vries and Florent-Treacy, 2002), technical expertise (Goldsmith and Walt, 1999), balancing global vs. local tensions (Rhinesmith, 1996; Tung and Mille, 1990; Black et al., 1999), hiring staff (Goldsmith and Walt, 1999), depth of field, professional expertise, and understanding and utilizing financial concepts and principles (Brake, 1997). The Knowledge of organization has been described as knowledge of worldwide organization (Black et al., 1999), total organization astuteness, recognizing the key constituencies and decision makers, and understanding the key organizational processes, systems, procedures, and methods (Brake, 1997), and linking activities and capabilities globally (Jordan and Cartwright, 1998). In addition, awareness of human resources available, training needs, strategic roles of different business units and competitive advantages world wide can be considered as a part of organizational knowledge. The knowledge of business is referred to as knowledge of the company's worldwide business structure, knowledge of international business issues (Caligiuri and Di Santo, 2001), coping with the interdependence of business activity around the world (Harris and Moran, 1987), understanding business systems (Barham and Wills, 1992; Birchall et al., 1996), recognizing business opportunities around the world (Black et al., 1999), understanding of international marketing and finance (Barham and Oates, 1991, Birchall et al., 1996), staying abreast of world standards of competition and knowing what it takes to match and beat those standards (Birchall et al., 1996), understanding the global nature of one's business and being able to analyze current trends/market conditions (Brake, 1997), and being able to conduct global SWOT analysis (Jordan and Cartwright, 1998; Bartlett and Ghoshal, 1992).

Finally, there is the knowledge of people, understanding the impact of cultural factors on behavioral communication (Harris and Moran, 1987). Noting the absence of consensus as to what being a global leader is all about Kets de Vries and Florent-Treacy (2002)) have concluded that it is "only when leaders establish a state of complementarity with the universal motivational need systems [compare with Maslow (1954)] of their followers (whatever the national culture may be) that a global corporation comes into full bloom". One of the main priorities of the global leaders they interviewed for their research was to "establish and maintain a corporate culture that transcends cultural differences and establishes "beacons" - values and attitudes that are comprehensible and compelling for employees with diverse backgrounds and cultural differences". To be able to do this, the most effective global leaders need to understand and connect with the universal basics of human functioning (Kets de Vries and Florent-Treacy, 2002). This insight into the needs, goals, demands and problems of different organizational constituents (Mumford et al., 2000) is also related to appreciating cultural differences, ability to manage diversity and cross-cultural ethics, recognizing the skills of others, finding, hiring and motivating staff with diverse cultural backgrounds, creating safe, positive environment for change, and developing reward systems and performance goals that tap and are in harmony with different norms and values of other cultures.

What about experience? Experience is often recognized as the most important predictor of the level of the current global leadership skills. According to several studies, (e.g. Boyacigiller, 1991; Gregersen et al., 1998; McCall and Hollenbeck, 2002) the most effective training takes place "hands-on", by means of, e.g. expatriation or international assignments, travel or participation in teams/task forces/action learning 
groups with people with diverse backgrounds (see also Carpenter et al., 2000; Gregersen et al., 1998; Seibert et al., 1995; Oddou et al., 2000; Roberts et al., 1998). Internationally experienced managers who are responsive to global opportunities and threats are also viewed as a source of competitive advantage (e.g. Gregersen et. al., 1998; Pucik, 1992; Seibert et al., 1995; Oddou et al., 2000; Derr, 1993; Odenwald, 1993).

Several empirical studies provide support to the organizational benefits of international work experience. Black et al. (1999) have found a positive relationship between the level of employee internationalization and firm's return on net assets. Carpenter et al. (2000 and 2001) found that US multinationals with international assignment-experienced CEO performed better than those led by CEOs without such experience. Sambharya (1996) and Athanassiou and Nigh (2002) report that, within US multinationals, international experience is positively related to the extent of MNC's internationalization. Results of Elron's (1997) research of subsidiary top management teams of US multinationals, suggest that cultural heterogeneity of these teams contribute positively to subsidiary performance.

Personal experience can be assessed in terms of amount and type of the international interaction. However, in today's dynamic environment, managers cannot always rely on previous knowledge and experience (Gregersen et al., 1998; Harvey and Buckley, 2002). Because of this, experience as such may no longer prevail as a selection criterion. Furthermore, at the individual level, patterns of growth are complex and their variation is influenced by abilities, dispositional characteristics and type and timing of developmental experiences an individual is exposed to (Mumford et al., 2000). Yet, whereas the "hard" competencies gained through experience may become obsolete, the development of the "soft side" during foreign assignments may still increase the predictive value of the previous experience (see i.e. Stahl et al. 2002, Inkson and Arthur, 1997.

\section{Conclusions and implications}

The major aim of this paper was to review global leadership competency frameworks suggested in previous literature and to build a more integrative competency framework to be used in future research. Some general issues related to global leadership research were discussed first, and the more integrated framework was described in the chapters that followed. Despite the large number of studies carried out on critical success factors for international (in most cases expatriate) assignments there are only very few based on empirical research, attempting to test the validity of different items and the reliability of different measures. Results from previous studies accumulate into a long list of competencies characterized by only minor semantic differences of a much smaller number of key competencies (see also Jordan and Cartwright, 1998). Practically no longitudinal research has been reported that would validate the relevancy of different competencies defined. As a result, there is little agreement among researchers on the definition of global competence, its antecedents or outcomes (see also Beechler et al., 1999).

From human resource development perspective, this framework may provide the base for planning international training activities where the fundamental questions to be answered is: in what type of competencies development is needed, knowledge, skills and abilities, or other characteristics? It may be more important to understand the hierarchy of competencies than being able to draw a line between competencies and 
JEIT

29,3

212

contributing skills. Also in applying a competency framework, more emphasis should be put on learning and education instead of measurement, assessment and accreditation of specific competencies. In planning organizational development as well as career development activities the issues to be considered include: what are the most effective training methods to improve the competencies of a particular type, where can various training and developmental experiences be found, to whom should different developmental opportunities be offered, what measures can or should be used to assess the level of different competencies in an individual, and how the desired competencies can be retained and utilized within organization.

As for suggestions for further research, the review of the global leadership competencies brought forward several issues that call for attention. First of all, a more concise definition of "global leader" is needed, with adequate identification criteria, in order to create common understanding of the subject term. I.e. what organizational positions and geographical scopes of responsibility should be considered?

Second, in many studies, the target or reference group consists of "successful" individuals. This raises the question of how the success should be defined in global context, and to what extent then is this success related to the characteristics and actions of a particular individual? Here the key issues are identifying the appropriate performance criteria and time span to be used in such assessment. Short-term results may not be accurate predictors of long term success.

Third, in many instances the suggested global leadership competencies are based on conclusions drawn from conversations held during consultancy or training sessions with company representatives involved in international activities, or responsible for hiring people for such positions. Much more empirical research is needed to test the validity and relative importance of different competencies in practice. Comparative research is needed to understand better what successful global leaders do have that those less successful have not, or, what successful global leaders do not have that others do?

Fourth, based on the literature review, it seems that the suggested global leadership competencies are best described as continuums rather than dichotomies. Thus, instead of specific competencies, the focus should be on the extent of development of those competencies. In line with this, emphasis should be shifted from trying to define a specific list of competencies to defining and measuring their ideal levels in individuals.

Fifth, an objective could also be to define the "best practices" for developing different competencies. More longitudinal and comparative research is needed to understand the relationships and causalities between different competencies, their paths of development, and impact of different development methods.

Sixth, more understanding is needed about the importance of different types of previous experience to the development of global leadership competencies. According to the theories of traits and personality, major development of many key characteristics identified here takes place already in early childhood and adolescence. To what extend does early international experience predict a person's potential or end state global leadership competencies, and what is the relevance of different types of international experience? (see, for example, McCall and Hollenbeck, 2002.) From the point of view that global leadership competencies are not task, but context specific (that context being the global environment), childhood and family background should also be assessed as possible predictors of global leadership potential. 
Seventh, much of the individual development involves learning new things, skills and knowledge. Motivation is seen as fundamental and prerequisite for any learning to take place. Compared to the importance of motivation in a learning process, its role in the development of global leadership competencies has not gained much attention. More research is needed on possible relationships between the main motives behind accepting international or global responsibilities and performance, success and satisfaction when assessed from different perspectives. For example, are there differences in amount and pace of development between those highly motivated by the international aspects of the job itself and those driven mainly by other, instrumental motives such as economical incentives, promotion etc. not available when remaining in only domestic context?

I hope all these issues, together with the more integrative framework of global competencies provided in this paper, will stimulate curiosity and further research in this area.

\section{References}

Adler, N. (1983), "Typology of management studies involving culture", Journal of International Business Studies, Vol. 14 No. 2, pp. 29-48.

Adler, N.J. and Bartholomew, S. (1992), "Managing globally competent people", The Academy of Management Executive, Vol. 6 No. 3, pp. 52-65.

Athanassiou, N. and Nigh, D. (2002), "The impact of the top management team's international business experience on the firm's internationalization: social networks at work", Management International Review, Vol. 4 No. 2, pp. 157-81.

Barham, K. and Oates, D. (1991), The International Manager, The Economist Books, London.

Barham, K. and Wills, S. (1992), Management across Frontiers - Identifying the Competences of Successful International Managers, research report, Ashridge Management Research Group and the Foundation for Management Education, Berkhamsted.

Bartlett, C.A. and Ghoshal, S. (1989), Managing across Borders: The Transnational Solution, Harvard Business School Press, Boston, MA.

Bartlett, C.A. and Ghoshal, S. (1992), "What is a global manager?”, Harvard Business Review, Vol. 70 No. 5, pp. 124-32.

Baruch, Y. (2002), "No such thing as a global manager", Business Horizons, Vol. 45 No. 1, pp. 36-42.

Beechler, S., Taylor, S., Boyacigiller, N.A. and Lavy, O. (1999), "Building global mindset for competitive advantage: a conceptual integration of global mindset, international human resource management, and organizational performance in multinational corporations", paper presented at the International Management Division Annual Meeting of the Academy of Management Meetings, Chicago, IL, August.

Bennis, W.G. and Thomas, R.J. (2002), “Crucibles of leadership”, Harvard Business Review, Vol. 80 No. 9, pp. 39-45.

Bernhut, S. (2002), "Primal leadership with Daniel Goleman”, Ivey Business Journal, Vol. 66 No. 5 , pp. $14-15$.

Birchall, D., Hee, J.T. and Gay, K. (1996), “Competencies for international management", Singapore Management Review, Vol. 18 No. 1, pp. 1-13.

Black, J.S., Morrison, A.J. and Grgersen, H.B. (1999), Global Explorers: The next Generation of Leaders, Routledge, New York, NY. 
JEIT

29,3

214

Bonnstetter, B.J. (1999), "The DNA of global leadership competencies“, paper presented at the SHRM 22nd Annual Global HR Forum, Orlando, FL, 11-14 April.

Boyacigiller, N. (1991), "The international assignment reconsidered”, in Mendenhall, M. and Oddou, G. (Eds), Readings and Cases in International Human Resource Management, PWS Kent, Boston, MA, pp. 148-55.

Boyatzis, R.D., Goleman, D. and Rhee, K. (1999), "Clustering competence in emotional intelligence: insights from the emotional competence inventory (ECI) “, Consortium for Research on Emotional Intelligence in Organizations, available available at: www. eiconsortium.org

Brake, T. (1997), The Global Leader. Critical Factors for Creating The World Class Organization, Irwin Professional Publishing, Chicago, IL.

Brake, T., Walker, D. and Walker, T. (1995), Doing Business Internationally. The Guide to Cross-cultural Success, Irwin Professional Publishing, Burr and Ridge, IL.

Caligiuri, P. and Di Santo, V. (2001), "Global competence: what is it, and can it be developed through global assignments?”, Human Resource Planning, Vol. 24 No. 3, pp. 27-35.

Carpenter, M.A., Sanders, G.W. and Gregersen, H.B. (2000), "International assignment experience at the top can make a bottom-line difference", Human Resources Management, Vol. 39 Nos. 2/3, pp. 277-85.

Carpenter, M., Sanders, W.G. and Gregersen, H. (2001), "Building human capital with organizational context: the impact of international assignment experience on multinational firm performance and CEO pay", Academy of Management Journal, Vol. 44 No. 3, pp. 493-511.

Conner, J. (2000), "Developing global leaders of tomorrow”, Human Resource Management, Vol. 39 Nos. 2/3, pp. 147-57.

Coulson-Thomas, C. (1992), Creating the Global Company: Successful Internationalisation, McGraw Hill Europe, Maidenhead.

Derr, B.C. (1993), "Internationalizing managers: speeding up the process", European Management Journal, Vol. 11 No. 4, pp. 435-42.

Elron, E. (1997), "Top management teams within multinational corporations: effects of cultural heterogeneity", The Leadership Quarterly, Vol. 8 No. 4, pp. 393-412.

Engle, A.D., Mendenhall, M.E., Powers, R.L. and Stedham, Y. (2001), "Conceptualizing the global competency cube: a transnational model of human resource“, paper presented at the Global Human Resource Management Conference, Barcelona, June.

Evans, W.A., Hau, K.C. and Sculli, D. (1989), “A cross-cultural comparison of managerial styles”, The Journal of Management Development, Vol. 8 No. 3, pp. 5-13.

Goldsmith, M. and Walt, K. (1999), "New competencies for tomorrow's global leader", CMA Management, December/January, pp. 20-4.

Goleman, D. (1998), "What makes a leader”, Harvard Business Review, Vol. 76 No. 6, pp. 93-103.

Goleman, D. (2000), "Leadership that gets results”, Harvard Business Review, Vol. 78 No. 2, pp. 78-89.

Gregersen, H.B., Morrison, A.J. and Black, J.S. (1998), "Developing leaders for the global frontier", Sloan Management Review, Fall, pp. 21-32.

Gupta, A.K. and Govindarajan, V. (2002), "Cultivating global mindset”, Academy of Management Executive, Vol. 16 No. 1, pp. 116-26.

Harris, P.R. and Moran, R.T. (1987), Managing Cultural Differences, 2nd ed., Gulf Publishing Company, Houston, TX. 
Harvey, M. and Buckley, R.M. (2002), "Assesssing the 'conventional wisdoms' of management for the 21st Century organization”, Organizational Dynamics, Vol. 30 No. 4, pp. 368-78.

Inkson, K. and Arthur, M.B. (1997), "Expatriate assignment versus overseas experience: Contrasting models of international human resource development", Journal of World Business, Vol. 32 No. 4, pp. 351-68.

Jordan, J. and Cartwright, S. (1998), "Selecting expatriate managers: key traits and competencies”, Leadership \& Organization Development Journal, Vol. 19 No. 2, pp. 89-96.

Kets de Vries, M.F.R. and Florent-Treacy, E. (2002), "Global leadership from A to Z: creating high commitment organizations”, Organizational Dynamics, Vol. 295 No. 309, pp. 1-16.

Kotter, J.P. (1990a), A Force for Change: How Leadership Differs From Management, Free Press, New York, NY.

Kotter, J.P. (1990b), "What leaders really do”, Harvard Business Review, Vol. 68 No. 3, pp. 103-12.

Maslow, A. (1954), Motivation and Personality, Harper \& Row, New York, NY.

McBeath, G. (1990), Practical Management Development. Strategies for Management Resourcing and Development in the 1990s, Basil Blackwell, Oxford.

McCall, M.W. Jr and Hollenbeck, G.P. (2002), Developing Global Executives: The Lessons of International Experience, Harvard Business School Press, Boston, MA.

Meldrum, M. and Atkinson, S. (1998), "Meta-abilities and the implementation of strategy: knowing what to do is simply not enough", Journal of Management Development, Vol. 17 No. 8, pp. 564-75.

Mintzberg, H. (1975), "The manager's job: folklore and fact”, Harvard Business Review, Vol. 53 No. 4, pp. 49-61.

Moran, R.T. and Riesenberger, J.R. (1994), The Global Challenge: Building the New Worldwide Enterprise, McGraw-Hill Book Company, London.

Morrison, A.J. (2000), "Developing a global leadership model", Human Resource Management, Vol. 39 Nos. 2/3, pp. 117-32.

Morrison, A.J., Gregersen, H.B. and Black, S. (1999), "What makes savvy global leaders?”, IVEY Business Journal, Vol. 64 No. 2, pp. 44-51.

Mumford, M.D., Zaccaro, S.J., Harding, F.D. and Jacobs, A. (2000), "Leadership skills for a changing world: solving complex social problems”, Leadership Quarterly, Vol. 11 No. 1, pp. 11-35.

Oddou, G., Mendenhall, M.E. and Richie, J.B. (2000), "Leveraging travel as a tool for global leadership development”, Human Resource Management, Vol. 39 Nos. 2/3, pp. 159-72.

Odenwald, S.B. (1993), Global Training: How to Design a Program for Multinational Corporation, Business One Irwin, Homewood, IL.

Pucik, V. (1992), “Globalization and human resources management”, in Pucik, V., Tichy, N.M. and Bennett, C.K. (Eds), Globalizing Management. Creating and Leading the Competitive Organization, Wiley \& Sons, New York, NY.

Rhinesmith, S.H. (1996), A Manager's Guide to Globalization: Six Skills for Success in a Changing World, 2nd ed., The McGraw-Hill Companies, New York, NY.

Roberts, K., Kossek, E.E. and Ozeki, C. (1998), "Managing the global workforce: challenges and strategies", Academy of Management Executive, Vol. 12 No. 4, pp. 93-119.

Rosen, R.H. (2000), "What makes a globally literate leader?", Chief Executive, April, pp. 46-8.

Sambharya, R. (1996), "Foreign experience of top management teams and international diversification strategies of U.S. multinational corporations", Strategic Management Journal, Vol. 17 No. 9, pp. 739-46. 
JEIT

29,3

216

Schein, E.H. (1978), Career Dynamics: Matching Individual and Organizational Needs, Addison Wesley, Reading, MA.

Schein, E.H. (1985), Career Anchors - Discovering Your Real Values, Jossey-Bass/Pfeiffer, San Francisco, CA.

Seibert, K.W., Hall, D.T. and Kram, K.E. (1995), "Strengthening the weak link in strategic executive development: Integrating individual development and global business strategy", Human Resources Management, Vol. 34 No. 4, pp. 549-76.

Spreitzer, G.M., McCall, M.W. Jr and Mahoney, J. (1997), “The early identification of international executive potential”, Journal of Applied Psychology, Vol. 82 No. 1, pp. 6-29.

Srinivas, K.M. (1995), "Globalization of business and the third world: challenge of expanding the mindsets", Journal of Management Development, Vol. 14 No. 3, pp. 26-49.

Stahl, G.K., Miller, E.L. and Tung, R.L. (2002), “Toward the boundaryless career: a close look at the expatriate career concept and the perceived implications of an international assignment”, Journal of World Business, Vol. 37 No. 3, pp. 216-27.

Suutari, V. (2002), "Global leader development: an emerging research agenda", Career Development International, Vol. 7 No. 4, pp. 218-33.

Thaler-Certer, R.E. (2000), “Whither global leaders?”, HRM Magazine, Vol. 45 No. 5, pp. 82-6.

Tung, R.L. and Mille, E.L. (1990), "Managing in the twenty-first century: the need for global orientation", Management International Review, Vol. 30 No. 1, pp. 5-18.

Wills, S. and Barham, K. (1994), "Being an international manager", European Management Journal, Vol. 12 No. 1, pp. 49-58.

Yukl, G. (1994), Leadership in Organizations, 3rd ed., Prentice Hall, Englewood Cliffs, NJ.

\section{Further reading}

Boyacigiller, N. (1990), "The role of expatriates in the management of interdependence, complexity, and risk in multinational corporations", Journal of International Business Studies, Vol. 21 No. 3, pp. 357-81.

Goleman, D. (1995), Emotional Intelligence: Why it Can Matter More Than IQ, Bantam, New York, NY.

Kanter, R.M. (1995), World class: Thriving Locally in the Global Economy, Simon \& Schuster, New York, NY.

Kotter, J.P. (1999), John P. Kotter on What Leaders Really Do, Harvard Business School Press, Boston, MA.

Mintzberg, H. (1973), The Nature of Managerial Work, Prentice Hall, New York, NY.

Rosen, R.H., Digh, P., Singer, M. and Phillips, C. (2000), Global Literacies: Lessons on Business Leadership and National Cultures, Simon and Schuster, New York, NY.

Salovey, P. and Meyer, J.D. (1990), "Emotional intelligence", Imagination, Cognition and Personality, Vol. 9 No. 3, pp. 185-211.

Thorndike, E.L. (1920), “Intelligence and its uses”, Harper's Magazine, No. 140, pp. 227-35.

Tung, R.L. (1998), "American expatriates abroad: from neophytes to cosmopolitans", Journal of World Business, Vol. 33 No. 2, pp. 125-44.

Yau, W.S. and Sculli, S. (1990), "Managerial traits and skills", The Journal of Management Development, Vol. 9 No. 6, pp. 32-40. 